\title{
A Review of the Role of Mitochondrial Manganese Superoxide Dismutase in Human Disorders, such as, Diabetes
}

\author{
Annwyne Houldsworth*
}

Received: July 13, 2016; Accepted: September 01, 2016; Published: September 07, 2016

*Corresponding author: Annwyne Houldsworth, Associate Lecturer at Plymouth University, Optometry, School of Health Professions, Peninsula Allied Health Centre, PL6 8BU, UK, Tel: +01822 854322; E-mail: Annwyne.houldsworth@plymouth.ac.uk

\begin{abstract}
A review of the antioxidant gene manganese Superoxide Dismutase (SOD-2) and its association with disease processes, especially Diabetes Mellitus (DM) and diabetic complications. The endogenous antioxidant enzyme systems, such as observed with Superoxide Dismutase (SOD), helps to manage the levels of Reactive Oxygen Species (ROS) in a cell that are generated by the cell's respiratory reactions. The role of free radical reactions in protein oxidation, DNA damage and lipid peroxidation is strongly debated in relation to human disease and has been implicated in many disease states.
\end{abstract}

Keywords: SOD-2; Diabetes mellitus; Diabetic complications; Antioxidant enzymes; Antioxidant genes; Oxidative stress; Reactive oxygen species; Mitochondrial respiration

The effective treatment of DM and the prevention of diabetic complications may be improved by a better understanding of the antioxidant function of intracellular defences against (OS) stress. Polymorphisms in antioxidant genes may determine cellular OS levels as a primary pathogenic role in DM and/or in its complications. SOD-2 has been investigated in patients with several diseases, including type 1 DM (T1DM) to ascertain if specific genotypes have any protective influences in the pathogenic mechanisms in DM and/or in several different complications, including retinopathy, nephropathy and diabetic controls compared to normal healthy controls. A focus on the SOD-2 mitochondrial targeting sequence (Ala -9 Val substitution) found to be important in diabetic nephropathy.

The possibility that SOD-2 antioxidant supplementation in diseases caused by intracellular redox imbalance may be beneficial against disease processes is also explored.

The endogenous antioxidant enzyme systems, such as observed with Superoxide Dismutase (SOD) helps to manage the levels of Reactive Oxygen Species (ROS) in a cell. ROS are continuously being generated by the cell's mitochondrial respiratory reactions [1-4].

The role of free radical reactions in protein oxidation, DNA damage and lipid peroxidation is strongly debated in relation to human disease and has been implicated in many disease states.
It is not clear whether ROS are the sole and major cause of tissue damage in disease or if they need to be accompanied by other factors, including tissue injury. It is clear that free radical reactions occur more readily than normal in diseased or damaged tissues and this may exacerbate disease. Increased oxidisability of damaged tissues can be due to the inactivation or leakage of antioxidants from cells [4].

Proliferative cells that are exposed to sub-cytotoxic OS such as $\mathrm{H}_{2} \mathrm{O}_{2}, \mathrm{UV}$, ethanol etc. display mitochondrial DNA deletions, cell morphology, histochemistry changes, cell cycle regulation and gene expression differences [5]. Polymorphic genetic differences may change the antioxidant gene expression in a similar way to these somatic mutations caused by OS.

SOD, initially named erythrocuprein, was demonstrated in $1968 / 69$ to inhibit the xanthine oxidase mediated reduction of cytochrome c. The reduction of cytochrome $\mathrm{c}$ is initiated by the production of the superoxide anion $\left(\mathrm{O}^{2 \cdot-}\right)$, by xanthine oxidase in the presence of an electron donor such as xanthine, hypoxanthine or acetaldehyde [2,3].

\section{XOD}

Xanthine $+\mathrm{O}_{2} \rightarrow$ uric acid $+\mathrm{O}^{2}-$

$\mathrm{O}^{2}$ - + detector $\rightarrow$ oxidised/reduced detector

SOD

$2 \mathrm{O}^{2 \cdot-}+2 \mathrm{H}^{+} \rightarrow \mathrm{H}_{2} \mathrm{O}_{2}+\mathrm{O}_{2}$

The superoxide radical is converted into hydrogen peroxide by the action of superoxide dismutases.

MnSOD is involved in controlling dioxygen toxicity in the mitochondria, an organelle of extreme oxidative load. Overexpression of the antioxidant manganese Superoxide Dismutase (SOD-2) abolished the signal generated by ROS [6].

There is an early molecular event involving an increase in mitochondrial mass and mtDNA content in response to exogenous and endogenous Oxidative Stress (OS) [5]. Enzymic systems are part of a cell's line of defence against the lethal or mutagenic damage caused by OS by removing ROS from the cell 
and involves enzymes, such as, catalytic Superoxide Dismutases (SOD); Copper/ Zinc-dependent SOD (CuZnSOD), in the cytosol, manganese-dependent SOD (MnSOD), in the mitochondria, and catalase (CAT), in the cytosol and peroxisomes [7,8]. Interestingly, high levels of ROS, facilitated by enzymes, such as, SOD-2 enhance mitochondrial Hydrogen Peroxide $\left(\mathrm{mtH}_{2} \mathrm{O}_{2}\right)$ and are normally linked to dedifferentiation of somatic cells [9]. SOD catalyses the dismutation of hydrogen peroxide and superoxide into oxygen, enabling cell repair and reducing the damage inflicted by OS. Hydrogen peroxide is further broken down to water by catalase or peroxidase. ROS induces this antioxidant enzyme expression in tissues but defective production or action could result in OS and ROS tissue damage ultimately leading to cell death [10].

Misregulation of physiological mitochondrial systems, such as, enzymic regulation of ROS and reduction of the accumulation of oxidative damage are thought to be key players in the roles of aging processes and metabolic diseases. Mitochondrial research has revealed the importance of antioxidant mechanisms in the mitochondria, cell survival and cell death regulation, in addition to their role in energy production and the signalling systems associated with them [11].

Redox homeostasis, regulated by the mitochondria, is thought to be involved in triggering apoptosis and senescence. ROS in the mitochondria appears to regulate cell responses to environmental stressors, oncogenes and nutrients and p53 (tumour suppressor gene) orchestrates redox signalling in the mitochondria, in conjunction with SOD-2 and the ROS generator, p66shc [12].

\section{Different forms of SOD}

This antioxidant enzyme is found in at least three forms, one is in the mitochondria, one in the cytosol and another in the endoplasm. In the genetic organisation of members of the human SOD enzyme family, SOD-3 has some homology between SOD-1 and SOD-3. SOD-2 has no significant amino acid sequence homology with SOD-1 or SOD-3 [13] (Figure 1). Several metal ions are associated with antioxidant enzymes, such as, copper, zinc, manganese or iron.

Manganese superoxide dismutase (SOD-2) is found in the mitochondria in nearly all cells and with a molecular mass of $40,000 \mathrm{kDa}$, it consists of four subunits each of which probably contains a manganese atom. SOD-2 has been localised to chromosome 6 (6q25) [14] and some of the features of the SOD-2 gene are typical of housekeeping genes [15].

The complete genomic structure shows marked conservation between human, rat and mouse species. Physically the SOD2 gene consists of 5 exons and 4 introns [16]. In all the species studied there are no TATA or CAAT boxes identified but the GCrich regions are present in all species $[17,18]$. There are putative $\mathrm{NF}-\mathrm{KB}$ transcription regulatory elements in the human and mouse genes. In humans this is in the 3 '-flanking region of the gene [16] whereas the mouse contains two potential elements in the 5'-flanking region [17]. There are also multiple copies of Sp-1 and AP- 2 consensus sequences in the promoter region of several species.
Decreased levels of SOD-2 may contribute to the development of certain diseases. Mice without the gene that encodes SOD-2 die 10 days after birth with cardiomyopathy and lipid accumulation in the liver and skeletal muscles [19]. Thus SOD-2 is essential for aerobic life where the lack of that function is fatal. In animal cells decreased SOD-2 and catalase levels were observed in breast cancer, adenomas and leukaemia [20].

Differences in antioxidant expression may explain a predisposition of a patient with diabetes to diabetic complications such as nephropathy, neuropathy, cardiovascular disease or retinopathy. ROS are increasingly formed in Diabetes Mellitus (DM) by the auto-oxidation of glucose and glycosylated proteins. Hyperglycaemia leads to the activation of the polyol pathway and contributes to the formation of triose phosphate and its autooxidation, which results in $\alpha$-oxaldehyde and $\mathrm{H}_{2} \mathrm{O}_{2}$ [21]. Defective antioxidant expression may be partly due to polymorphic differences in the genes encoding the antioxidant enzymes. There is growing evidence to suggest that polymorphisms in the promoter region of the Aldose Reductase gene (ALR2) are associated with susceptibility to nephropathy, retinopathy and neuropathy and differing levels of the gene's expression $[22,23]$. SOD-2 may also determine the extent of liver damage resulting from HCV infection [24]. SOD-2 blood levels are significantly reduced in patients with viral hepatitis, regardless of the viral etiology.

\section{SOD-2 and DM}

An SOD-2 targeting signal sequence polymorphism has been identified on chromosome 6q 25 and may be in linkage with the susceptibility genes IDDM5 (6q22) and IDDM8 (6q27), discovered by Todd when screening the human genome for T1DM related genes [25]. A polymorphism in the mitochondrial targeting signal

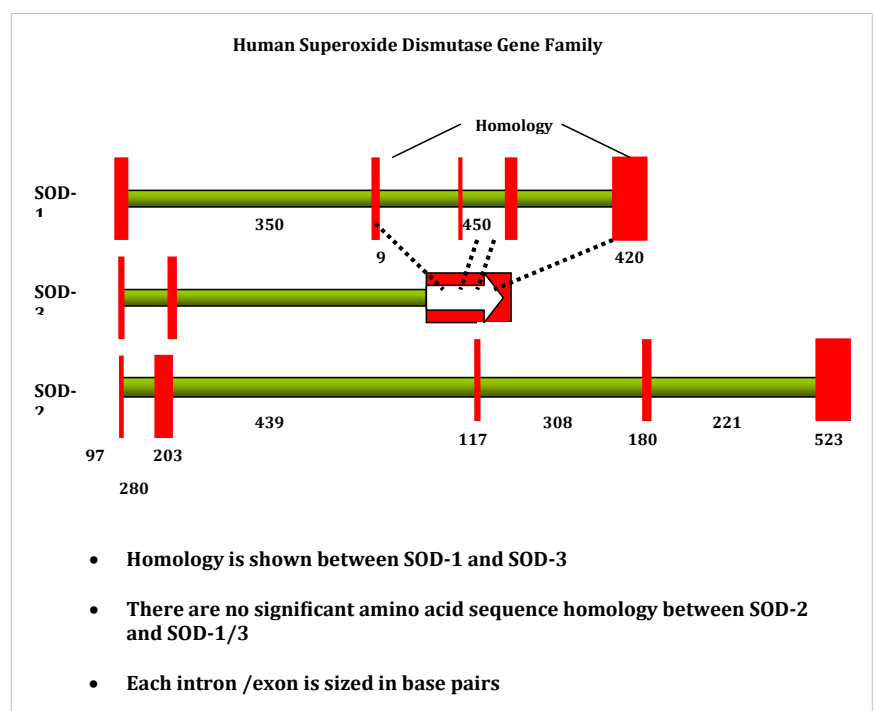

Figure 1: It is adapted from Zelko, et al [13] and shows the genetic organisation of members of the human SOD enzyme family. SOD-3 has been placed in the middle in order to demonstrate the homology between SOD-1 and SOD-3. SOD-2 has no significant amino acid sequence homology with SOD-1 or SOD-3. The number of base pairs of each exon and intron is shown in association with each fragment. 
sequence could affect the transport of the enzyme through the mitochondrial membrane and a defect may alter the membrane receptor recognition site resulting in less of the enzyme protein entering the cell thus lowering the antioxidant response to OS.

Ala/Ala homozygotes for a polymorphism in the SOD-2 mitochondrial targeting sequence (Ala -9 Val substitution) has been found to be significantly lower for patients with diabetic nephropathy (DN) than patients without nephropathy whereas the Val/Val genotype was significantly higher in the DN group in a Russian cohort [26]. Different results have been observed in different populations and ethnic differences have been observed with this polymorphism [27]. The $\mathrm{T}$ allele relates to the valine amino acid, which is considered to have a lower basal level of SOD-2 activity according to Chistyakov 2001, but there is little experimental evidence to back this hypothesis yet.

High glucose levels trigger an intracellular antioxidant response that is mediated by SOD- 1 and 2, catalase and glutathione peroxidases. Oscillating glucose levels, s experienced by patients with DM, induce injurious effects on endothelial cells, although the mechanism of this is not well understood it is accepted that oxidative damage occurs during the process [28].

Antioxidant responses to hyperglycaemia have shown that SOD-2 responses did not change between diabetic patient complication groups or in normal controls. There was however a twofold increase in the expression of catalase under hyperglycaemic conditions suggesting that high glucose flux through aldose reductase inhibits the expression of antioxidant enzymes [29].

There is more than one sequence for mitochondrial targeting which suggests a combination mechanism for the vital enzyme determining rates of targeting, membrane translocation and signal sequence cleavage with concomitant folding of the SOD2 protein $[30,31]$. The variation in amino acid from alanine to valine in the SOD-2 leader signal affects the processing efficiency of the enzyme. The amino acid change is thought to give a conformational change from an alpha helix to a beta sheet and this may result in mistargeting due to poor receptor recognition. The valine form may be less efficiently transported into the mitochondria than the alanine form of the enzyme. Studies have indicated that basal SOD-2 activity is highest for Ala/Ala, followed by Ala/Val and then Val/Val [26,32]. It is postulated that the functional polymorphism V16A affects the localisation of MnSOD into the mitochondrial matrix and therefore its ability to scavenge superoxide radicals [32].

There are a number of recognised polymorphisms in the mitochondrial targeting sequence for SOD-2 that have been widely investigated, one is an alanine/valine substitution at the -9 position and another is an Ile to Thr substitution at position 58. The latter substitution elicits a 3-fold decrease in SOD-2 enzyme activity and reduces the tumour suppressor effect of the enzyme [33].

It has been assumed that this polymorphism may impair subcellular localization of SOD-2 but there is no experimental evidence that supports this $[31,34]$.
The Val(16)Ala version of the gene disrupts the proper targeting of the SOD-2 from the cytosol to the mitochondrial matrix where it acts on superoxide radicals and dismutate them to hydrogen peroxide. Changes in the levels of both superoxide and hydrogen peroxide, in mitochondria, modulates the molecular mechanisms of apoptosis, cellular adhesion, and cell proliferation and thus play key role in cancer development [34].

There are other conditions that polymorphic differences in SOD-2 gene are associated with, such as, a genetic polymorphism of the SOD-2 gene, which may be associated with increased risk of breast cancer among Chinese women. These patients were examined for the SOD-2 Val-9Ala polymorphism of the mitochondrial targeting sequence [35]. A study investigating a Finnish population found a 1.5 fold increase in breast cancer associated with this ala-9 Val polymorphism. Also bladder cancer has been associated with a SOD-2 polymorphism [36]. A significant difference in the C-9-T genotype was observed between patients and normal controls but not between diabetic controls and patients with complications. In a study to ascertain if specific

Genotypes have any protective influences in the pathogenic mechanisms in diabetes and/or in several different complications, there were significantly more of the diabetic controls than the patients with diabetic nephropathy the 'c allele' appeared to be protective against diabetic nephropathy [37].

The same polymorphism is also associated with premature aging or progeria [29] and with an increased risk of sporadic motor neuron disease, especially in females [26]. Although Parkinsonism and ALS have been investigated for associations with this polymorphism, none have been found [30,32,38].

\section{SOD-2 transcription factors}

SOD-2 is a highly regulated gene despite the fact that it is ubiquitously expressed at relatively high levels. The gene is regulated by a variety of intracellular and environmental stimuli (Figure 2). Many compounds induce SOD-2 transcription including cytokines such as IL-1, IL-4, IL-6, TNF- $\alpha$, lipopolysaccharide (LPS) and IFN- $\gamma$ [39]. Intron 2 holds the cytokine inducible enhancer regions where binding sites for NFкB, C/EBP and NF-1 transcription are located [40]. Manganese ions at high concentrations are highly toxic to cells and induce SOD-2 expression in human breast cancer [41].

It has been reported that the microtubule-active anticancer drugs such as taxol and vincristine also induce SOD-2 expression via activation of a CREB-1/ATF-1 like factor but not AP-1 or NFKB [40]. Many cancers result in gene methylation of the intronic region of SOD-2 and results in a reduced expression of SOD-2 [42].

There is also a posttranscriptional regulation of SOD2 expression by an RNA-binding protein, located in the 3' untranslated ( $41 \mathrm{bp}$ region) part of SOD-2 mRNA. The identity of the RNA-binding protein has not been identified. The positioning of this cis acting element can greatly increase the translational efficiency and enzyme activity of the reporter gene [42-44]. 


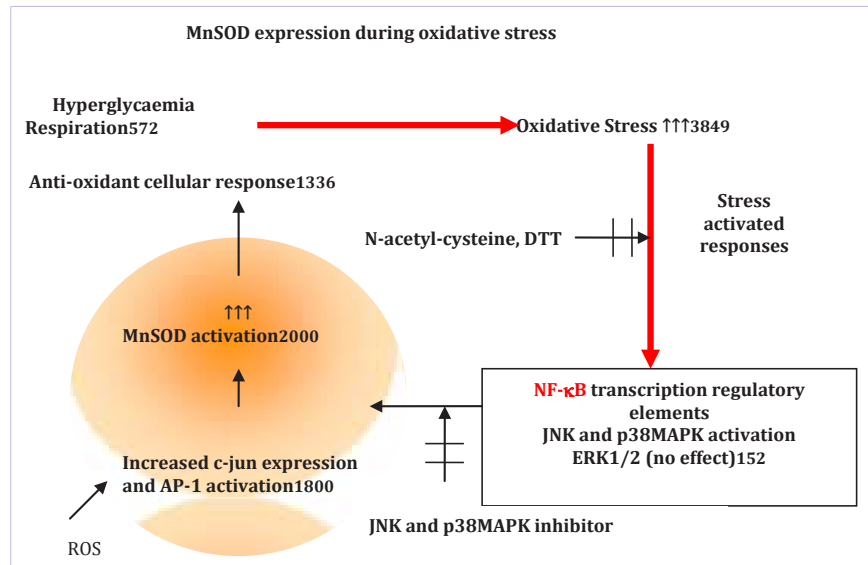

Figure 2: Shows the proposed actions of the free radical induced cascade of stress-activated responses in cells via activation of p38 MAPK, JNK and AP-1 that contribute to increased levels of SOD-2 expression. JNK and p38 inhibitors block the activation of SOD-2 expression.

The administration of oral supplementation of SOD-2 has been investigated and GliSODin is Superoxide Dismutase (SOD) extracted from melons and combined with gliadin. When mice received this it was found to promote antioxidant defenses in the brain and to prevent stress induced impairment of memory and in other animal studies, it was concluded that supplementation with gliadin-combined standardized melon SOD extract (Glisodin) promoted the cellular antioxidant status and protected against oxidative stress-induced cell death $[45,46]$. No concrete conclusions have been made about the health benefits of human SOD-2 supplementation and studies thus far all state that much larger studies are needed [47].

Future studies to consider may involve gene therapies to elevate the antioxidant function of the targeted tissue, such as, kidney in diabetic nephropathy, where enzymes are applied as pharmaceutical drugs to treat or prevent disease $[48,49]$.

\section{References}

1. Salin MLand McCord JM. Superoxide dismutases in polymorphonuclear leukocytes. J Clin Invest. 1974;56:1319.

2. McCord JM, Fridovich I. Superoxide dismutase. An enzymic function for erythrocuprein (hemocuprein). J Biol Chem. 1969;244(22):604955.

3. McCord JM. Free radicals and inflammation: protection of synovial fluid by superoxide dismutase. Science. 1974;185(4150):529-31.

4. Brownlee M. Biochemistry and molecular cell biology of diabetic complications. Nature. 2001;414(6865):813-20.

5. Entrez Gene:SOD2 superoxide dismutase 2, mitochondrial

6. Lee HC, Yin PH, Lu CY, Chi CW, Wei YH. Increase of mitochondria and mitochondrial DNA in response to oxidative stress in human cells. Biochem. J. 2000;348:425-32.

7. Clapperton M, McMurray J, Fisher AC, Dargie HJ. Does luminol chemiluminescence detect free radical scavengers? $\mathrm{Br} \mathrm{J}$ Clin Pharmacol. 1995;39(6):688-91.

8. Michiels C, Raes M, Toussaint 0 , Remacle J. Importance of Seglutathione Antioxidant gene expression, peroxidase, catalase and
$\mathrm{Cu} / \mathrm{Zn}$ SOD for cell survival against oxidative stress. Free Radical Biol. Med. 1994;17:235-248.

9. He C, Hart PC, Germain D, Bonini MG. SOD2 and the Mitochondrial UPR:Partners Regulating Cellular Phenotypic Transitions. Trends Biochem Sci. 2016;41(7):568-77. doi: 10.1016/j.tibs.2016.04.004.

10. Beckman KB, Ames BN. The Free Radical Theory of Aging Matures. Physiol Rev. 1998;78(2):547-81.

11.Lakshminarasimhan M, Steegborn C. Emerging mitochondrial signalling mechanisms in physiology, aging processes, and as drug targets. Exp Gerontol. 2011;46(2-3):174-7. doi: 10.1016/j. exger.2010.08.024.

12. Pani G, Galeotti T. Role of MnSOD and p66shc in mitochondrial response to p53. Antioxid Redox Signal. 2011;15(6):1715-27. doi: 10.1089/ars.2010.3499.

13.Zelko IN, Mariani TJ, Folz R. J. Superoxide dismutase multigene family:a comparison of the CuZn-SOD (SOD1), Mn-SOD (SOD2), and EC-SOD (SOD3) gene structures, evolution, and expression. Free Radic Biol Med. 2002;33(3):337-49.

14. Church SL, Farmer DR, Nelson DM. Induction of manganese superoxide dismutase in cultured human trophoblast during in vitro differentiation. Dev. Biol. 1992;149(1):177-84.

15. Dynan WS, Sazer S, Tjian R, Schimke RT. Transcription factor Sp1 recognizes a DNA sequence in the mouse dihydrofolate reductase promoter. Nature. 1986;319(6050):246-8.

16. Wan XS, Devalaraja MN, St Clair DK. Molecular structure and organization of the human manganese superoxide dismutase gene. DNA Cell Biol.1994;13(11):1127-36.

17. Jones PL, Kucera G, Gordon H, Boss JM. Cloning and characterization of the murine manganous superoxide dismutase-encoding gene. Gene. 1995;153(2):155-61.

18. Jones WR, Johnston DS, Stone MP. Refined structure of the doubly intercalated d(TATAFBGCATA)2 aflatoxin B1 adduct. Chem Res Toxicol. 1998;11(8):873-81.

19. Li Y, Huang TT, Carlson EJ, Melov S, Ursell PC, Olson JL, et al. Dilated cardiomyopathy and neonatal lethality in mutant mice lacking manganese superoxide dismutase. Nat Genet. 1995;11(4):376-81.

20.Sun Y, Oberley LW, Elwell JH, Sierra-Rivera E. Lowered antioxidant enzymes in spontaneously transformed embryonic mouse liver cells in culture. Carcinogenesis. 1993;14(7):1457-1463.

21. Negre-Salvayre A, Salvayre R, Augé N, Pamplona R, Portero-Otín M. Hyperglycemia and Glycation in Diabetic Complications. Antioxidants \& Redox Signaling. 2009;11(12):3071-3109.

22. Demaine AG, Cross DF, Millward A. Polymorphisms of the aldose reductase gene and susceptibility to retinopathy in type 1 diabetes mellitus. Invest Ophthalmol Vis Sci. 2000;41(13):4064-4068.

23. Heesom AE, Millward BA, Demaine AG. Susceptibility to diabetic neuropathy in patients with insulin-dependent diabetes mellitus is associated with a polymorphism at the 5_ end of the aldose reductase gene. J Neurol Neurosurg Psychiatry. 1998;64(2):213-216.

24. Houldsworth A, Metzner M, Shaw S, Kaminski E, Hodgkinson A, Demaine AG, Cramp ME. Polymorphic Differences in SOD-2 May Influence HCV Viral Clearance. J Med Virol. 2014;86(6):941-7. doi: 10.1002/jmv.23923.

25. Todd JA, Farrall M. Panning for gold:genome-wide scanning for linkage in type 1 diabetes. Hum Mol Genet. 1996;5:1443-8. 
26. Chistyakov DA, Savost'anov KV, Zotova EV, Nosikov VV.Polymorphisms in the Mn-SOD and EC-SOD genes and their relationship to diabetic neuropathy in type 1 diabetes mellitus. 4. BMC Med Genet. 2001;2:4.

27. Van Landeghem GF, Tabatabaie P, Kucinskas V, Saha N, Beckman G. Ethnic variation in the mitochondrial targeting sequence polymorphism of MnSOD. Hum Hered. 1999;49(4):190-3.

28. La Sala L, Cattaneo M, De Nigris V, Pujadas G, Testa R, Bonfigli AR, et al. Oscillating glucose induces microRNA-185 and impairs an efficient antioxidant response in human endothelial cells. Cardiovasc Diabetol. 2016 30;15(1):71. doi:10.1186/s12933-016-0390-9.

29. Hodgkinson AD, Bartlett T, Oates PJ, Millward BA, Demaine AG The response of antioxidant genes to hyperglycemia is abnormal in patients with type 1 diabetes and diabetic nephropathy. Diabetes. 2003;52(3):846-51.

30. Rosenblum JS, Gilula NB, Lerner RA. On signal sequence polymorphisms and diseases of distribution. Proc Natl Acad Sci U S A. 1996;93(9):4471-3.

31. Shimoda-Matsubayashi S, Matsumine H, Kobayashi T, NakagawaHattori Y, Shimizu Y, Mizuno Y. Structural dimorphism in the mitochondrial targeting sequence in the human manganese superoxide dismutase gene. A predictive evidence for conformational change to influence mitochondrial transport and a study of allelic association in Parkinson's disease. Biochem Biophys Res Commun. 1996;226(2):561-5.

32. Sutton A, Khoury H, Prip-Buus C, Cepanec C, Pessayre D, Degoul F. The Ala16Val genetic dimorphism modulates the import of human manganese superoxide dismutase into rat liver mitochondria. Pharmacogenetics. 2003;13(3):145-157.

33. Tomblyn M, Kasarskis EJ, Xu Y, St Clair DK. Distribution of MnSOD polymorphisms in sporadic ALS patients. J Mol Neurosci. 1998;10(1):65-6.

34. Miriyala S, Holley AK, St Clair DK. Mitochondrial superoxide dismutase-signals of distinction. Anticancer Agents Med Chem. 2011;11(2):18190.

35. Cai Q, Shu XO, Wen W, Cheng JR, Dai Q, Gao YT, et al. Genetic polymorphism in the manganese superoxide dismutase gene, antioxidant intake, and breast cancer risk: results from the Shanghai Breast Cancer Study. Breast Cancer Res. 2004;6(6):R647-55.

36. Hung RJ, Boffetta P, Brennan P, Malaveille C, Gelatti U, Placidi D, et al. Genetic polymorphisms of MPO, COMT, MnSOD, NQO1, interactions with environmental exposures and bladder cancer risk. Carcinogenesis. 2004;25(6):973-8.

37. Houldsworth A, Hodgkinson A, Millward BA, Demaine AG. Polymorphic differences in the SOD-2 gene may affect the pathogenesis of nephropathy in patients with diabetes and diabetic complications., Gene. 2015;569(1):41-5. doi: 10.1016/j.gene.2015.04.006.

38. Farin FM, Hitosis Y, Hallagan SE, Kushleika J, Woods JS, Janssen PS, et al. Genetic polymorphisms of superoxide dismutase in Parkinson's disease. Mov Disord. 2001;16(4):705-7.

39. Harris CA, Derbin KS, Hunte-McDonough B, Krauss MR, Chen KT, Smith $\mathrm{DM}$, et al. Manganese superoxide dismutase is induced by IFN-gamma in multiple cell types. Synergistic induction by IFN-gamma and tumor necrosis factor or IL-1. J Immunol. 1991;147(1):149-54.

40. Jones PL, Ping D, Boss JM. Tumor necrosis factor alpha and interleukin1 beta regulate the murine manganese superoxide dismutase gene through a complex intronic enhancer involving C/EBP-beta and NFkappaB. Mol Cell Biol. 1997;17(12):6970-81.

41. Thongphasuk J, Oberley LW, Oberley TD. Induction of superoxide dismutase and cytotoxicity by manganese in human breast cancer cells. Arch Biochem Biophys. 1999;365(2):317-27.

42. Kim HP, Roe JH, Chock PB, Yim MB. Transcriptional activation of the human manganese superoxide dismutase gene mediated by tetradecanoylphorbol acetate. J Biol Chem. 1999;274(52):37455-60.

43. Huang Y, Peng J, Oberley LW, Domann FE. Transcriptional inhibition of manganese superoxide dismutase (SOD2) gene expression by DNA methylation of the 5' CpG island. Free Radic Biol Med. 1997;23(2):31420.

44. Knirsch L, Clerch LB. A region in the 3' UTR of MnSOD RNA enhances translation of a heterologous RNA. Biochem Biophys Res Commun. 2000;272(1):164-8.

45. Vouldoukis I, Conti M, Krauss P, Kamate C, Blazquez S, Tefit M, et al. Supplementation with gliadin-combined plant superoxide dismutase extract promotes antioxidant defenses and protects against oxidative stress. Phytother Res. 2004;18(12):957-62.

46. Nakajimaa S, Ohsawaa I, Nagata K, Ohtaa S, Ohnob M, Ijichic T, etal. Oral supplementation with melon superoxide dismutase extract promotes antioxidant defences in the brain and prevents stress-induced impairment of spatial memory. Behav Brain Res. 2009;200(1):15-21.

47. Romao S. Therapeutic value of oral supplementation with melon superoxide dismutase and wheat gliadin combination. Nutrition. 2015;31(3):430-6.

48. Vellard M. The enzyme as drug:application of enzymes as pharmaceuticals. Curr Opin Biotechnol. 2003;14(4):444-50.

49. Carillon J, Rouanet JM, Cristol JP, Brion R. Superoxide dismutase administration, a potential therapy against oxidative stress related diseases:several routes of supplementation and proposal of an original mechanism of action. Pharm Res. 2013;30(11):2718-28. doi:10.1007/ s11095-013-1113-5. 